\title{
Impact of Cell Density on Differentiation Efficiency of Rat Adipose-derived Stem Cells into Schwann-like Cells
}

\author{
Mahtab Maghzi Najafabadii, ${ }^{1,2}$, Vahid Bayati ${ }^{1,2}$, Mahmoud Orazizadeh ${ }^{1,2}$, \\ Mahmoud Hashemitabar ${ }^{1,2}$, Forouzan Absalan ${ }^{1,2}$ \\ ${ }^{1}$ Cellular and Molecular Research Center, ${ }^{2}$ Department of Anatomical Sciences, Faculty of Medicine, \\ Ahvaz Jundishapur University of Medical Sciences, Ahvaz, Iran
}

Background and Objectives: Schwann-like (SC-like) cells induced from adipose-derived stem cells (ASCs) may be one of the ideal alternative cell sources for obtaining Schwann cells (SCs). They can be used for treating peripheral nerve injuries. Co-culture with SCs or exposure to glial growth factors are commonly used for differentiation of ASCs to SC-like cells. However, the effect of initial cell density as an inductive factor on the differentiation potential of ASCs into the SC-like cells has not been yet investigated.

Methods and Results: ASCs were harvested from rat and characterized. The cells were seeded into the culture flasks at three different initial cell densities i.e. $2 \times 10^{3}, 4 \times 10^{3}$ and $8 \times 10^{3} \mathrm{cells} / \mathrm{cm}^{2}$ an overnight and differentiated toward SC-like cells using glial growth factors. After two weeks, the differentiation rate of ASCs to SC-like cells at different densities was assessed by immunofluorescence, fluorescence-activated cell sorting analysis and real time RT-PCR. Expression of the typical SCs markers, S-100 proteins and glial fibrillary acidic protein (GFAP) protein, was observed in all cell densities groups although the number of S100-positive and GFAP-positive cells, and the expression of $\mathrm{p} 75^{\mathrm{NTR}}$ mRNA, another SC marker, were significantly higher at the density of $8 \times 10^{3} \mathrm{cells} / \mathrm{cm}^{2}$ when compared with the other cell densities groups $(\mathrm{p}<0.001)$.

Conclusions: The results suggest that the higher differentiation rate of ASCs to SC-like cells can be obtained at initial cell density of $8 \times 10^{3}$ cells $/ \mathrm{cm}^{2}$, possibly via increased cell-cell interaction and cell density-dependent influence of glial growth factors.

Keywords: Adipose-derived stem cell, Schwann cells, Differentiation, Initial cell density

\section{Introduction}

SCs as glial cells of the peripheral nervous system are

Accepted for publication August 12, 2016, Published online November 30, 2016

Correspondence to Vahid Bayati

Cellular and Molecular Research Center, Ahvaz Jundishapur University of Medical Sciences, Ahvaz 61357-15794, Iran Tel: +98-9125332499, Fax: +98-6133738628

E-mail: bayati-v@ajums.ac.ir,vahid_bayati@yahoo.com

(a) This is an open-access article distributed under the terms of the Creative Commons Attribution Non-Commercial License (http://creativecommons.org/ licenses/by-nc/4.0/), which permits unrestricted non-commercial use, distribution, and reproduction in any medium, provided the original work is properly cited. key regulators of the regeneration process of the injured nervous tissue. They provide structural support and guidance for peripheral nerve regeneration by releasing neurotrophic factors (1). SCs can be harvested through nerve biopsies for autologous transplantation. However, there are obstacles on way of clinical application of isolated SCs because one or more functional nerves are sacrificed by this aggressive procedure and additional morbidity will also take place. In addition, cultured SCs have also a limited mitotic activity in vitro, so the cell expansion become a time consuming process (2). ASCs are an attractive source for cell-based therapies. These cells are able to self-renew with a high growth rate and to differentiate along several mesenchymal cell lineages, including adipo- 
cytes, osteoblasts, myocytes, chondrocytes, endothelial cells and cardiomyocytes $(3,4)$. ASCs have also capability to be induced into neurospheres and neuronal-like cells in vitro (5). Previous studies have reported that ASCs can be induced into SC-like cells $(6,7)$. Other studies have also shown that the differentiated ASCs can myelinate neurons in vitro and provide functional benefits for peripheral nerve repair $(2,6)$. SC-like cells are bi- or tri-polar in shape and immunopositive for nestin and SC markers p75, GFAP and S-100, like genuine SCs $(8,9)$.

It is noteworthy that many factors have impact on differentiation process of mesenchymal stem cells (MSCs). These include soluble growth factors and cytokines (10, 11), mechanical stimuli (12), substrate properties (13), and culture conditions (14). Initial cell seeding density as one of the culture conditions, has been indicated to have tremendous effect on cell proliferation, differentiation, and extracellular matrix (ECM) synthesis (15-21). Rate of cytokine production is also shown to be dependent on cell density (22). Furthermore, it was declared that cell density had impact on biosynthesis of ECM such as collagen (23, 24), yielded higher alkaline phosphatase and produced more mineralization during cell differentiation (17). Of note, the growth patterns of MSCs cultures have been reported to be dependent on the initial plating densities. Interestingly, MSCs can grow as very dense colonies at low cell density, whereas MSCs spread evenly across the culture dish at high cell density $(17,22)$. It was reported that human MSCs at low density had a high potential for osteogenesis, whereas cells at high density had a propensity to become differentiated into adipocytes (25). Some researchers have proved that cell density influences MSCs expansion (26, 27). Aforementioned studies imply that cell density as an impressive factor can promote cell proliferation and differentiation. So far, no literature has revealed the effect of initial cell density on ASCs differentiation into SC-like cells. Accordingly, the goal of the current study was to investigate the effect of initial cell seeding density on SC-like cells differentiation of ASCs.

\section{Materials and Methods}

\section{Isolation and culture of ASCs}

This study was an experimental research. Ten Wistar rats (Male, 8 weeks, weight 150 200 g) were collectively obtained from laboratory animal research center of Ahvaz Jundishapur University of Medical Sciences (AJUMS) for all experimental groups. They were maintained under standard conditions of controlled temperatures $\left(23^{\circ} \mathrm{C}\right)$ and a light/dark cycle (12/12 hour) in the animal house of
Anatomical Sciences department, AJUMS. It should be mentioned that all experiments were performed in accordance with the protocols approved by the Institutional Animal Care and Use Committee and with the guidelines for care and use of experimental animals required by AJUMS. After rats were sacrificed, their gonadal fat pads were excised, and rat ASCs were isolated using a published method (12). Briefly, the adipose tissue was carefully dissected and digested using $0.1 \%$ collagenase type I (Gibco, USA) for 50 minutes. The cell suspension was centrifuged two times to separate the floating adipocytes from the stromal vascular fraction (SVF). Then, SVF cells were cultivated in Dulbecco's modified Eagle's medium (DMEM; Gibco, USA) supplemented with 10\% fetal bovine serum (FBS; Gibco, USA) 1\% penicillin/strepromicine (Sigma, USA) and $2 \mathrm{mM} \mathrm{L-glutamine} \mathrm{(Gibco,} \mathrm{USA).} \mathrm{After}$ 24 hours, the non-adherent cells were discarded by replacing the medium with that of fresh. Rat ASCs were passaged four times before being used for the experiments. Of course, the mesenchymal nature of isolated ASCs was approved by examining their surface antigens (CD44, CD73, and CD90 (as positive markers) and CD45 (as a negative marker)) and testing their differentiation potential into osteogenic and adipogenic cell lineages.

\section{Flow cytometric characterization of ASCs}

Rat ASCs at $4^{\text {th }}$ passage were harvested by trypsinization, then the cells were fixed in neutralized $2 \%$ paraformaldehyde (PFA) (Sigma, USA) solution for 30 minutes. The fixed cells were rinsed twice with $\mathrm{PBS}(\mathrm{Ca} / \mathrm{Mg}$-free Phosphate-buffered saline, PH 7.2) (Gibco, USA) and incubated with the following antibodies: CD90, CD73, CD44 (positive markers) and CD45 (negative marker) (all from eBiosciences, USA) for 30 minutes. Primary antibodies were directly conjugated with FITC. For isotype control, nonspecific FITC-conjugated IgG was substituted for the primary antibodies. Flow cytometry analysis was performed on the fluorescence-activated cell sorting (FACS) Vantage SE (BD Biosciences, USA) and the data were analyzed using FlowJo Cytometry Analysis Software (version 7.6.4).

\section{Differentiation potential assay}

We used rat ASCs at $4^{\text {th }}$ passage to determine the multipotential differentiation capacity of the cells. Cells were grown to at least $80 \%$ confluency before being cultured in the induction medium. To commence the osteogenic differentiation, rat ASCs were cultured in DMEM supplemented with $10 \%$ FBS, $0.1 \mu \mathrm{M}$ dexamethasone, $50 \mu \mathrm{M}$ ascorbate-2-phosphate, $10 \mathrm{mM}$ beta-glycerophosphate (All purchased from Sigma, USA) for 21 days. Then, cells were 
fixed with 4\% PFA for 30 minutes, rinsed by Hank's balanced salt solution (HBSS) (Gibco, USA) containing 1\% BSA (Gibco, USA), and incubated with $0.1 \%$ Alizarin Red $\mathrm{S}$ (Sigma, USA) solution to stain for calcium deposition. For adipogenic differentiation, subconfluent passage 4 cultures of ASCs were incubated in adipogenic induction medium (high glucose-DMEM containing 10\% FBS, $1 \mu \mathrm{M}$ dexamethasone, $0.5 \mathrm{mM}$ methyl-isobutylxanthine, $10 \mu \mathrm{g} / \mathrm{ml}$ insulin, and $100 \mu \mathrm{M}$ indomethacin (All purchased from Sigma, USA)) for 2 weeks. Cells were fixed with 4\% PFA for 60 minutes, rinsed by PBS, and then incubated in $0.3 \%$ Oil Red O (Sigma, USA) solution in 60\% isopropanol for 20 minutes to visualize neutral lipid droplets inside the cells.

\section{Experimental groups and differentiation protocol}

After cell counting, cells were cultivated at three different initial cell densities $\left(2 \times 10^{3}, 4 \times 10^{3}\right.$ and $8 \times 10^{3}$ cells $\left./ \mathrm{cm}^{2}\right)$ on separate Poly D-Lysine (PDL) coated $25 \mathrm{~cm}^{2}$ flasks overnight and on the next day, were incubated in SCs differentiation medium for 14 days as previously described (28). Briefly, subconfluent ASCs at passage $4^{\text {th }}$ were cultured in a medium supplemented with $1 \mathrm{mM} \beta$-mercaptoethanol (Sigma, USA) for 24 hours. Then, the cells were rinsed and fresh medium containing 10\% FBS and 35 $\mathrm{ng} / \mathrm{ml}$ all-trans-retinoic acid (Sigma, USA) was replaced. After 72 hours, the cells were rinsed and the medium was replaced with differentiation medium comprising of DMEM/Ham's F-12, 10\% FBS, $5 \mathrm{ng} / \mathrm{ml}$ platelet-derived growth factor (PDGF; PeproTech, UK), $10 \mathrm{ng} / \mathrm{ml}$ basic fibroblast growth factor (b-FGF; PeproTech, UK), $14 \mu \mathrm{M}$ forskolin (FSK; Sigma, USA) and $200 \mathrm{ng} / \mathrm{ml}$ recombinant human heregulin-b1 (HRG-bl; R\&D Systems, USA). The cells were incubated for 10 days to achieve full differentiation while the medium was changed every 3 days. Finally, immunofluorescence, FACS analysis and real time RT-PCR were employed for detection of proteins markers and the number of SC-like cells, respectively.

\section{Immunofluorescence}

For immunophenotype characterization of differentiated ASCs, the SCs markers, including S-100 and GFAP, were examined $(6,9)$. Undifferentiated (negative control) and differentiated ASCs at three different initial cell densities were fixed by $4 \%$ PFA for 20 minute and permeabilized with $0.05 \%$ Triton X-100 for 10 minute. Nonspecific binding sites were blocked using 3\% bovine serum albumin (BSA) for 2 hours. Then, anti-GFAP ( $1: 300$, Abcam, UK) and anti-S-100 protein (1:300, Abcam, UK) were added, and the cells were incubated overnight at $4^{\circ} \mathrm{C}$. FITC-con- jugated anti-mouse secondary antibody (Sigma, USA) was incubated with the cells at room temperature for 1 hour. Cell nuclei were labeled with DAPI. Finally, the cells were observed with a fluorescence microscope (BX51, OLYMPUS) and photographed.

\section{FACS analysis of glial differentiation}

Glial differentiation was quantitatively analyzed with FACS for S100 and GFAP. For FACS, cells were detached and stained sequentially with primary antibodies (mouse Anti-GFAP and anti-S-100 protein) and secondary antibody (FITC goat anti-mouse). Cells were fixed with $2 \%$ formaldehyde until analysis with FACS. For detection of intracellular proteins, cells were permeabilized by ice cold methanol for each sample at $-20^{\circ} \mathrm{C}$ for 10 minutes and then centrifuged and rinsed two times in PBS 1\% BSA before staining with primary mouse anti-S100 and antiGFAP and FITC-conjugated secondary antibodies.

\section{Detection of P75 ${ }^{\mathrm{NTR}}$ mRNA expression}

Expression of $\mathrm{P} 75^{\mathrm{NTR}}$ as a marker of SCs was detected by real-time PCR. P75 ${ }^{\text {NTR }}$ primers sequences were designed to span exon/intron junctions using primer express software (version 2.5) as follows: Forward 5'-CCT CAT TCC TGT CTA TTG CTC CAT C-3' and Reveres 5'-TTC CTC ACC TCC TCA CGC TTG G-3'. Total RNA was extracted from cells using Rneasy mini kit (Qiagen, MD, USA), subjected with Dnase (Qiagen, MD, USA) and quantified. cDNA was synthesized using QuantiTect ${ }^{\circledR}$ Reverse Transcription kit (Qiagen, MD, USA) according to manufacturer's instruction. PCR reactions were performed in 96 well plates with an ABI PRISM 7300 Sequence Detection System (Applied Biosystems, CA, USA) using SYBR Green to monitor amplification. PCR reactions were performed in triplicate. Real-time PCR data were analyzed with the manufacturer's software (Invitrogen). Results were expressed as $\mathrm{p} 75^{\mathrm{NTR}} \mathrm{mRNA}$ relative expression to $\beta$-actin as internal reference.

\section{Statistical analysis}

To analyze data, SPSS software version 17 was employed. The experiments were replicated at least three times. Data were presented as mean \pm SEM. One way ANOVA was employed to compare the rate of ASCs differentiation into SC-like cells at initial cell densities of 2000, 4000 and 8000 cell $/ \mathrm{cm}^{2}$. A value of $\mathrm{p} \leq 0.05$ was considered statistically significant. 


\section{Results}

Rat gonadal adipose tissue was enzymatically digested, centrifuged to isolate the SVF from mature adipocytes and plated. After the cells adhered to $25-\mathrm{cm}^{2}$ flasks, non-adherent cells, such as red blood cells, were removed by changing the culture medium after 24 hours. The initially adherent cells grew into spindle or stellate-shaped cells, which then developed into visible colonies 3 days after the initial plating. The cells began to proliferate rapidly and formed confluent fibroblast-like monolayers on flasks after approximately 1 week in culture. Cells were passaged by trypsination every $3 \sim 4$ days whereas they adopted a homogeneous morphology. After 4 passages, they were plated for differentiation potential assays. After treating ASCs by certain induction media, they could undergo adipogenic and osteogenic differentiation. Adipogenic differentiation was confirmed by the presence of Oil red O-positive va-
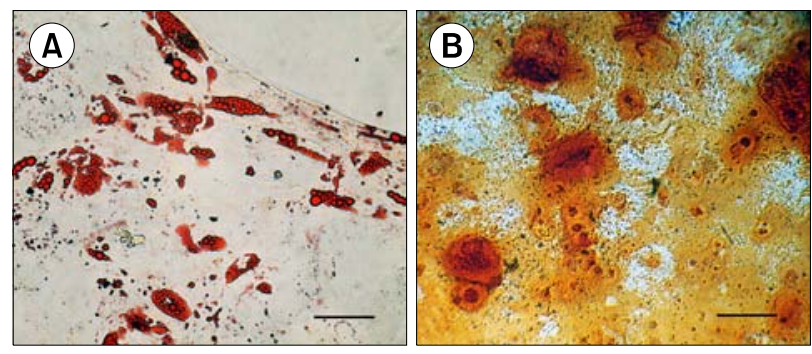

\section{C}
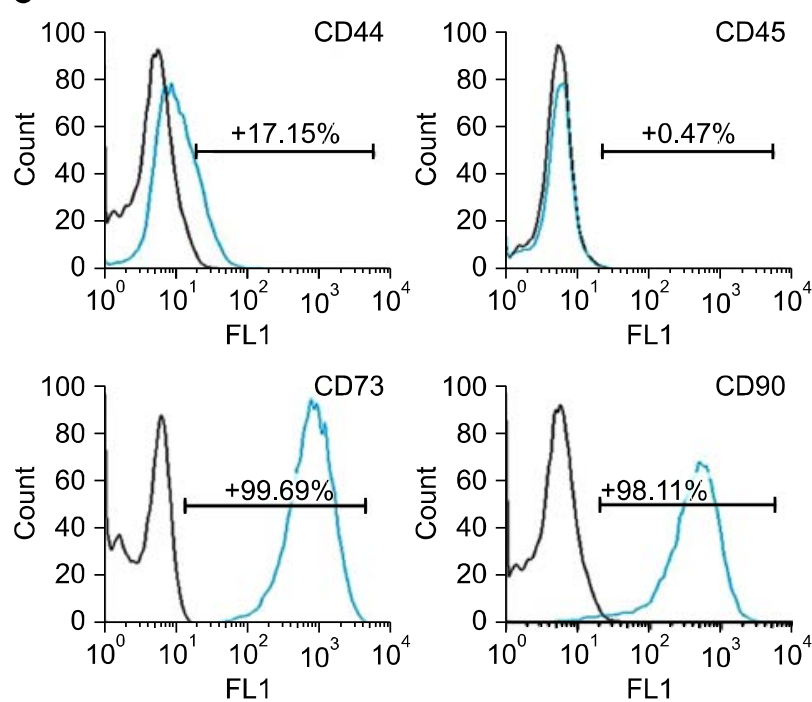

Fig. 1. The mesenchymal nature of isolated ASCs was confirmed by their ability to differentiate into adipogenic (A) and osteogenic (B) pathways and also by evaluating the expression rate of positive (CD44, CD73 and CD90) and negative (CD45) markers on the cells surface by flow cytometry (C). Scale bar $=10 \mu \mathrm{m}$. cuoles droplets (Fig. 1A) and osteogenic differentiation by the production of calcium deposits detected with Alizarin Red S (Fig. 1B). Flow cytometry analysis of rat ASCs at $4^{\text {th }}$ passage showed that they were immunologically positive for CD44 (17.15\%), CD73 (99.69\%) and CD90 (98.11\%), and negative for CD45 (0.47\%) (Fig. 1C). These techniques demonstrated the mesenchymal nature of isolated rat ASCs.

ASCs at three initial cell densities were treated with a mixture of glial growth factors for a period of 2 weeks. At the end, their immunophenotypes were detected for the expression of the specific SCs proteins, GFAP and S100. After commencement of the differentiation, cells morphology started to change so that some cells assumed a bipolar, spindle-shaped cells or tripolar shapes, similar to SCs. To investigate whether these morphological changes were resulted from the expression of the SCs proteins, we examined the expression of SCs markers (GFAP and S100) by immunofluorescence (Fig. 2). Immunofluorescence demonstrated that a varying number of cells expressed GFAP and S100 in all experimental groups of various initial cell densities. None of these markers was detected in undifferentiated negative control. To calculate the number of differentiated cells in each cell densities groups accurately, FACS analysis was performed (Fig. 3A). Quantitative analysis indicated that $\mathrm{S} 100$-positive cells were significantly higher at cell density of $8000(29.92 \pm 2.3 \%)$ as compared to the density of $4000(17.15 \pm 1.6 \%)$ and $2000(5.88 \pm 1.3 \%)$ $(\mathrm{p}<0.001)$. Similarly, most of the GFAP-positive cells existed at cell density of $8000(25.85 \pm 3.5 \%)$ as compared to the density of $4000(16.41 \pm 1.3 \%)$ and $2000(1.44 \pm 0.3 \%)$ $(\mathrm{p}<0.001)$ (Fig. 3B).

P75 ${ }^{\text {NTR }}$ mRNA expression was upregulated at 2000, 4000 and 8000 cell density after 14 days $(7.94 \pm 0.29,21.15 \pm$ 1.12 , and $32.58 \pm 0.75$, respectively). Although there was a significant difference among groups at 14 days, $\mathrm{p} 75^{\mathrm{NTR}}$ mRNA expression remained significantly higher at 8000 cell density than those of the other groups $(p<0.001)$.

\section{Discussion}

The present study demonstrated that a low cell density like $2 \times 10^{3}$ cells $/ \mathrm{cm}^{2}$ resulted in a low rate of SC differentiation while the seeding density of $8 \times 10^{3}$ cells $/ \mathrm{cm}^{2}$ appeared to be more efficient and appropriate, yielding a highest level of SC differentiation and glial markers expression. It seemed that the cells probably needed each other and relied on each other to become differentiated. In the recent years, ASCs have become a more attractive alternative for cell therapy. The accessible source, easy 

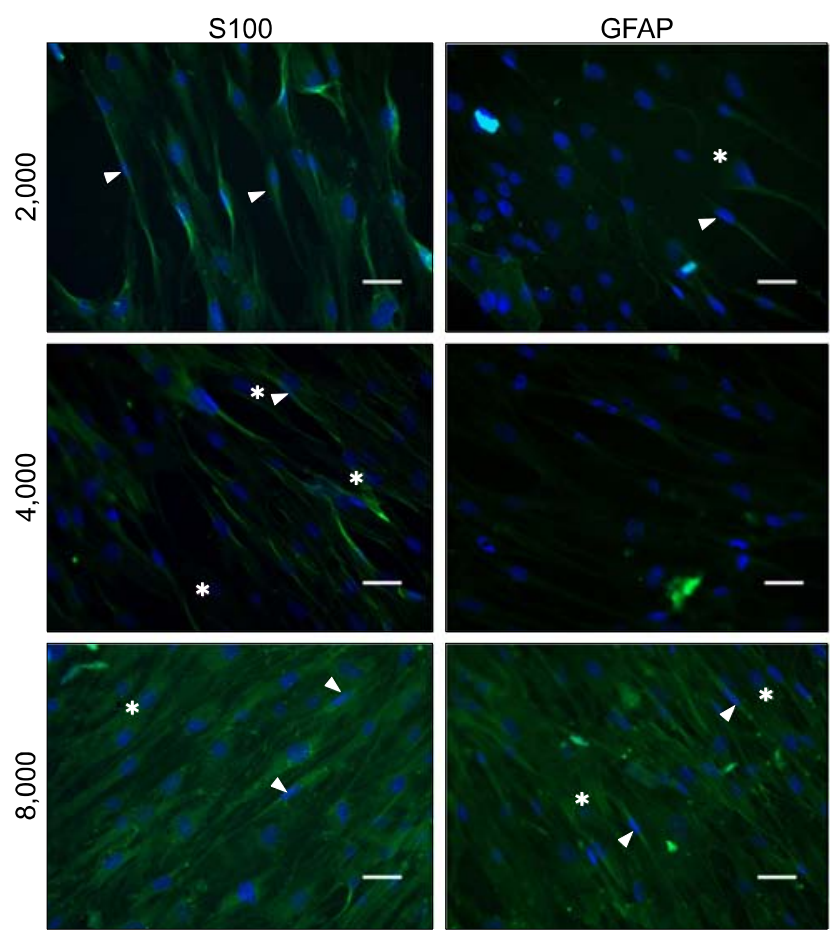

harvesting and rapid cell expansion account for the use of ASCs over the other sources of stem cells $(12,28)$. It seemed that the enhanced cell-cell interaction was necessary for ASCs differentiation into SC-like cells. Previously, it was reported that a cocktail of glial growth factors (containing GGF/HRG, FSK, PDGF and bFGF) could induce ASCs into SC-like cells which had a distinctive morphology and specific markers (GFAP, S100 and p75) (6, 8) and promoted nerve regeneration in vivo and in vitro (29). In addition, it was declared that SCs expanded when they were cultured with FSK and SCs mitogens or serum, whereas cell division was lost when the cells were cultured with FSK alone i.e. without any mitogens and serum (30). FSK can enhance intracellular cyclic adenosine monophosphate (cAMP). cAMP signal can act as a crucial intracellular signal during several stages of SCs development. In cultured SCs, cAMP elevation can simulate SCs performances in the presence of axons during myelination in vivo (31). Moreover, FSK can elevate the sensitivity of SCs to mitogens (32). SCs proliferation in response to mitogens was observed only when the cells were also treated with agents elevating cAMP levels $(33,34)$. Elevation of cAMP levels failed to motivate Schwann cell expansion in the absence of HRG. HRG is a subtype of neuregulin-1. Neuregulin-1 is now thought to play important roles in Schwann cell survival, differentiation and proliferation during development $(35,36)$. It is evident that SCs are responsive to HRG, and HRG-dependent growth has been

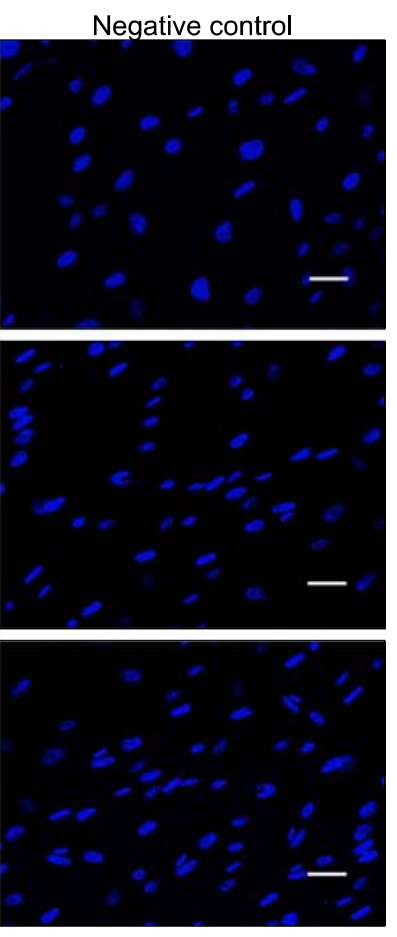

Fig. 2. Immunostaining of the cells cultured in Schwann cell differentiation medium after 2 weeks. Immunofluorescence demonstrated that some cells displayed bipolar and tripolar morphologies and expressed S100 and GFAP proteins at the center of differentiated cell colonies in all cell density groups. In addition, negative control images showed no expression of S100 and GFAP proteins. Arrow heads point to bipolar cells and asterisks show tripolar cell morphology. Scale bar $=30 \mu \mathrm{m}$. determined to be further stimulated by FSK $(37,38)$. In fact, SCs treated by HRG/FSK in vitro can grow to very high densities; however, the rate of growth is markedly decreased at these densities indicating that a cell density-dependent mechanism such as the production of an autocrine inhibitor or contact inhibition alters the SC responsiveness to mitogen. Therefore, it is regarded that HRG/FSK-induced growth of SCs in vitro is strongly regulated by cell density. Furthermore, several studies have elucidated that the impact of neural differentiation factor on cells is dose-dependent and that HRG as neural differentiation factor can improve proliferation as long as its concentration remains in a saturated range. When its dose diminished in culture medium after being metabolized by the cells, differentiation commences (35-39). These findings agree with our results. It seems that HRG at higher cell density $\left(8000\right.$ cells $/ \mathrm{cm}^{2}$ ) promotes cell differentiation but its concentration evokes proliferation at lower cell density (2000 cells $/ \mathrm{cm}^{2}$ ).

Furthermore, cell density has been shown to influence cell-cell interaction and as a critical factor, controls subsequent cell proliferation and gene expression profiles (20). In addition, cell proliferation is precisely tuned by surface area of cell attachment and contact-inhibition between adjacent cells (40-42). Despite of the fact that high cell density enhances cell-cell contact, contact-inhibition by gap junction alleviates cellular proliferation $(43,44)$. In addition, previous studies have shown that low initial 
A
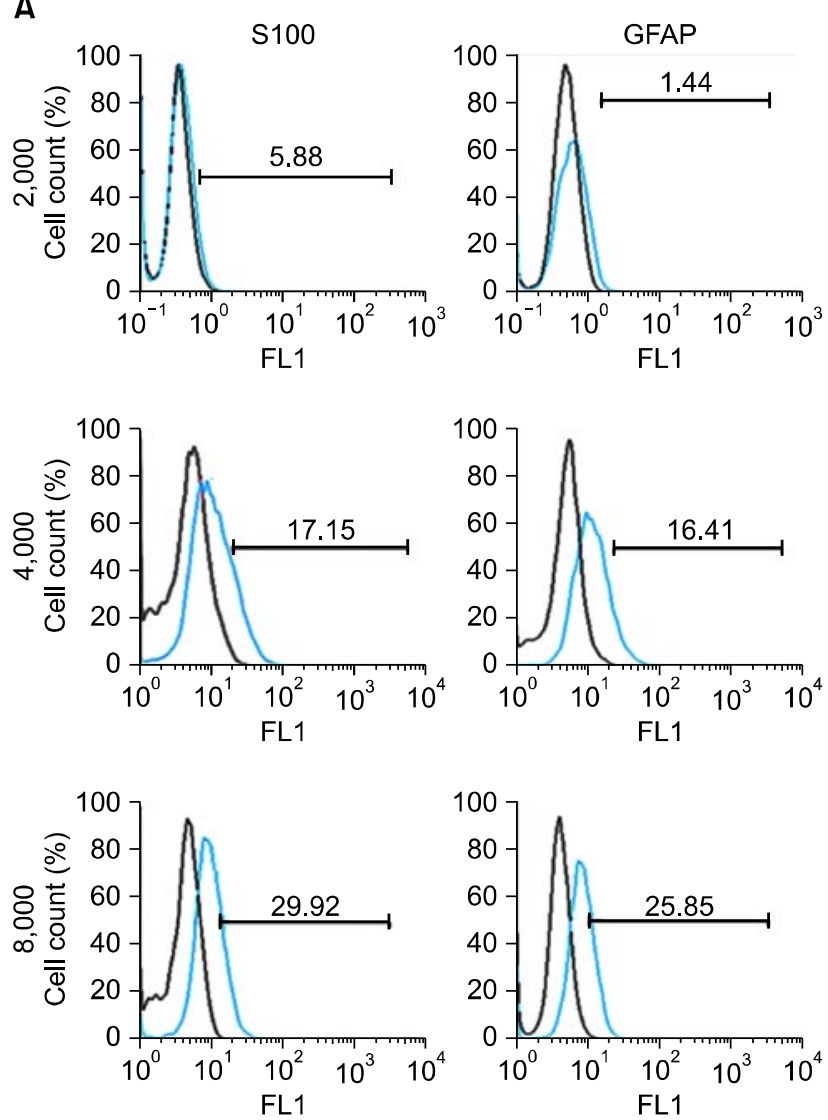
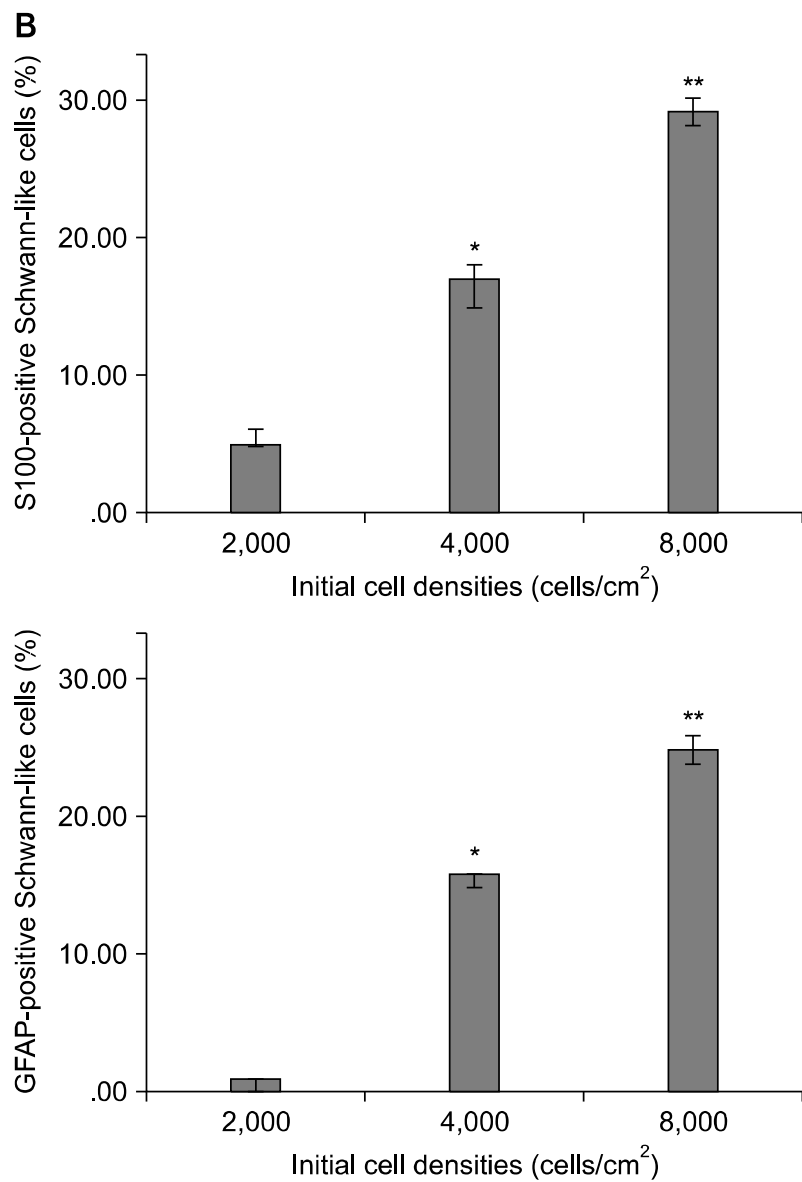

Fig. 3. FACS analysis of differentiated ASCs. (A) After 2 weeks of induction, cultures with different cell densities were analyzed by FACS for S100 and GFAP to indicate the number of differentiated SC-like cells. (Data are mean \% cells \pm SEM). (B) Quantitative analysis of cells expressing S100 and GFAP at different initial cell density groups. ${ }^{*} \mathrm{p}<0.001$ as compared to $2000 \mathrm{cells} / \mathrm{cm}^{2} ;{ }^{* *} \mathrm{p}<0.001$ as compared to 4000 cells $/ \mathrm{cm}^{2}$.

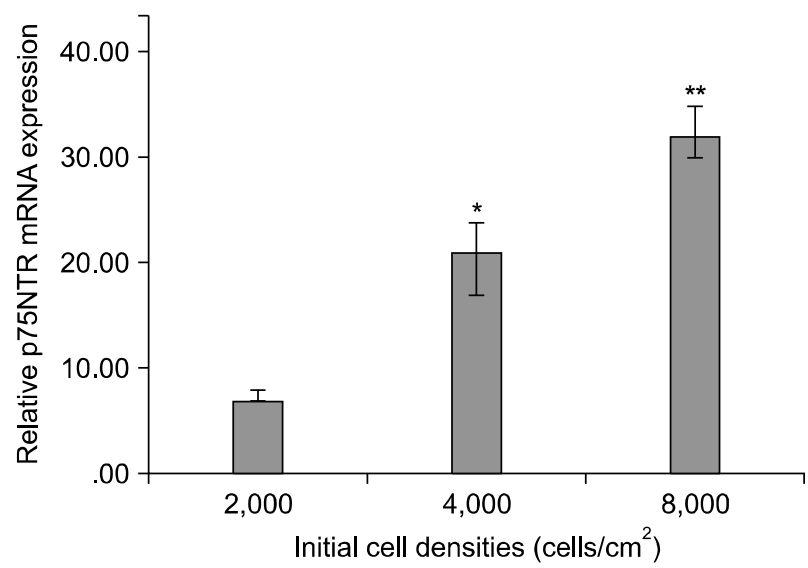

Fig. 4. Comparative analysis of $P 75^{\mathrm{NTR}}$ marker examined by real time RT-PCR at different initial cell density groups. ${ }^{*} p<0.001$ as compared to 2000 cells $/ \mathrm{cm}^{2} ;{ }^{* *} \mathrm{p}<0.001$ as compared to 4000 cells $/ \mathrm{cm}^{2}$. cell density of MSCs result in higher cell yields and faster expansion $(27,45)$. Cells seeded at low density yield more doublings in each passage, as growth inhibited by density-dependent mechanism at higher density. It has also been reported that cell density alters cell shape that changes an adipogenic-osteogenic switch in MSCs lineage commitment. Previous studies declared that if the cell density was below the optimal one, increasing the cell density promoted cell function such as bone marker expressions; when the cell density exceeded the optimal one, a further increase in cell density decreased cell function and tissue regeneration $(20,46)$. Two competing factors appear to be operative here; one factor is that the cells communicate with each other for cell-cell interactions, intercellular signal molecules and synthesizing more ECM to maintain their viability and function at a high level. This factor was intensively active at low to medium cell densities. The other factor was that high cellularity lead 
to contact-inhibition, lack of oxygen and nutrients and inefficient waste removal. These studies are consistent with our results. It seems that high cell density $\left(8000 \mathrm{cells} / \mathrm{cm}^{2}\right)$ elicited contact inhibition, attenuated cell proliferation and stimulated ASCs differentiation towards SC-like cells.

\section{Conclusions}

We concluded that the high cell density like 8000 cells $/ \mathrm{cm}^{2}$ would be optimal for SC differentiation from ASCs, yielding a high percentage of SC-like cells with the highest glial markers expression, possibly due to increased cell-cell contact in favor of differentiation induction and cell density-dependent effect of glial growth factors like HRG.

\section{Acknowledgments}

This work was the MSc thesis of Mahtab Maghzi Najafabadi and was funded by Grant No. 117, from Cellular and Molecular Research Center (CMRC-117), Ahvaz Jundishapur University of Medical Sciences (AJUMS), Ahvaz, Iran.

\section{Potential conflict of interest}

The authors have no conflicting financial interest.

\section{References}

1. Wiberg M, Terenghi G. Will it be possible to produce peripheral nerves? Surg Technol Int 2003;11:303-310

2. Xu Y, Liu L, Li Y, Zhou C, Xiong F, Liu Z, Gu R, Hou $\mathrm{X}$, Zhang C. Myelin-forming ability of Schwann cell-like cells induced from rat adipose-derived stem cells in vitro. Brain Res 2008;1239:49-55

3. Gimble JM, Katz AJ, Bunnell BA. Adipose-derived stem cells for regenerative medicine. Circ Res 2007;100:1249-1260

4. Zuk PA, Zhu M, Ashjian P, De Ugarte DA, Huang JI, Mizuno H, Alfonso ZC, Fraser JK, Benhaim P, Hedrick $\mathrm{MH}$. Human adipose tissue is a source of multipotent stem cells. Mol Biol Cell 2002;13:4279-4295

5. Sofroniew MV, Howe CL, Mobley WC. Nerve growth factor signaling, neuroprotection, and neural repair. Annu Rev Neurosci 2001;24:1217-1281

6. Kingham PJ, Kalbermatten DF, Mahay D, Armstrong SJ, Wiberg M, Terenghi G. Adipose-derived stem cells differentiate into a Schwann cell phenotype and promote neurite outgrowth in vitro. Exp Neurol 2007;207:267-274

7. Ning H, Lin G, Lue TF, Lin CS. Neuron-like differentiation of adipose tissue-derived stromal cells and vascular smooth muscle cells. Differentiation 2006;74:510-518

8. Pourheydar B, Joghataei MT, Bakhtiari M, Mehdizadeh M, Yekta Z, Najafzadeh N. Co- transplantation of bone mar- row stromal cells with schwann cells evokes mechanical allodynia in the contusion model of spinal cord injury in rats. Cell J 2012;13:213-222

9. Tomita K, Madura T, Sakai Y, Yano K, Terenghi G, Hosokawa K. Glial differentiation of human adipose-derived stem cells: implications for cell-based transplantation therapy. Neuroscience 2013;236:55-65

10. Otto TC, Lane MD. Adipose development: from stem cell to adipocyte. Crit Rev Biochem Mol Biol 2005;40:229-242

11. Bowers RR, Lane MD. A role for bone morphogenetic protein-4 in adipocyte development. Cell Cycle 2007;6:385-389

12. Bayati V, Sadeghi Y, Shokrgozar MA, Haghighipour N, Azadmanesh K, Amanzadeh A, Azari S. The evaluation of cyclic uniaxial strain on myogenic differentiation of adipose-derived stem cells. Tissue Cell 2011;43:359-366

13. Guo L, Kawazoe N, Fan Y, Ito Y, Tanaka J, Tateishi T, Zhang X, Chen G. Chondrogenic differentiation of human mesenchymal stem cells on photoreactive polymer-modified surfaces. Biomaterials 2008;29:23-32

14. Song SJ, Jeon O, Yang HS, Han DK, Kim BS. Effects of culture conditions on osteogenic differentiation in human mesenchymal stem cells. J Microbiol Biotechnol 2007;17: 1113-1119

15. Almarza AJ, Athanasiou KA. Effects of initial cell seeding density for the tissue engineering of the temporomandibular joint disc. Ann Biomed Eng 2005;33:943-950

16. Wang L, Seshareddy K, Weiss ML, Detamore MS. Effect of initial seeding density on human umbilical cord mesenchymal stromal cells for fibrocartilage tissue engineering. Tissue Eng Part A 2009;15:1009-1017

17. Goldstein AS. Effect of seeding osteoprogenitor cells as dense clusters on cell growth and differentiation. Tissue Eng 2001;7:817-827

18. Bitar M, Brown RA, Salih V, Kidane AG, Knowles JC, Nazhat SN. Effect of cell density on osteoblastic differentiation and matrix degradation of biomimetic dense collagen scaffolds Biomacromolecules 2008;9:129-135

19. Kruyt M, De Bruijn J, Rouwkema J, Van Bliterswijk C, Oner C, Verbout A, Dhert W. Analysis of the dynamics of bone formation, effect of cell seeding density, and potential of allogeneic cells in cell-based bone tissue engineering in goats. Tissue Eng Part A 2008;14:1081-1088

20. Kim K, Dean D, Mikos AG, Fisher JP. Effect of initial cell seeding density on early osteogenic signal expression of rat bone marrow stromal cells cultured on cross-linked poly (propylene fumarate) disks. Biomacromolecules 2009;10: 1810-1817

21. Xu HH, Simon CG Jr. Fast setting calcium phosphate-chitosan scaffold: mechanical properties and biocompatibility. Biomaterials 2005;26:1337-1348

22. Takagi M, Umetsu Y, Fujiwara M, Wakitani S. High inoculation cell density could accelerate the differentiation of human bone marrow mesenchymal stem cells to chondrocyte cells. J Biosci Bioeng 2007;103:98-100

23. Yassin MA, Leknes KN, Pedersen TO, Xing Z, Sun Y, Lie SA, Finne-Wistrand A, Mustafa K. Cell seeding density is 
a critical determinant for copolymer scaffolds-induced bone regeneration. J Biomed Mater Res A 2015;103:3649-3658

24. Maia FR, Lourenço AH, Granja PL, Gonçalves RM, Barrias CC. Effect of cell density on mesenchymal stem cells aggregation in RGD-alginate 3D matrices under osteoinductive conditions. Macromol Biosci 2014;14:759-771

25. McBeath R, Pirone DM, Nelson CM, Bhadriraju K, Chen CS. Cell shape, cytoskeletal tension, and RhoA regulate stem cell lineage commitment. Dev Cell 2004;6:483-495

26. Both SK, van der Muijsenberg AJ, van Blitterswijk CA, de Boer J, de Bruijn JD. A rapid and efficient method for expansion of human mesenchymal stem cells. Tissue Eng 2007;13:3-9

27. Colter DC, Class R, DiGirolamo CM, Prockop DJ. Rapid expansion of recycling stem cells in cultures of plastic-adherent cells from human bone marrow. Proc Natl Acad Sci U S A 2000;97:3213-3218

28. Younesi E, Bayati V, Hashemitabar M, Azandeh SS, Bijannejad D, Bahreini A. Differentiation of adipose-derived stem cells into Schwann-like cells: fetal bovine serum or human serum? Anat Cell Biol 2015;48:170-176

29. Radtke C, Schmitz B, Spies M, Kocsis JD, Vogt PM. Peripheral glial cell differentiation from neurospheres derived from adipose mesenchymal stem cells. Int J Dev Neurosci 2009;27:817-823

30. Morgan L, Jessen KR, Mirsky R. The effects of cAMP on differentiation of cultured Schwann cells: progression from an early phenotype $(04+)$ to a myelin phenotype (P0+, GFAP-, N-CAM-, NGF-receptor-) depends on growth inhibition. J Cell Biol 1991;112:457-467

31. Kim HA, Ratner N, Roberts TM, Stiles CD. Schwann cell proliferative responses to cAMP and Nf1 are mediated by cyclin D1. J Neurosci 2001;21:1110-1116

32. Meyer-Franke A, Wilkinson GA, Kruttgen A, Hu M, Munro E, Hanson MG Jr, Reichardt LF, Barres BA. Depolarization and cAMP elevation rapidly recruit TrkB to the plasma membrane of CNS neurons. Neuron 1998;21:681-693

33. Kim HA, DeClue JE, Ratner N. cAMP-dependent protein kinase $\mathrm{A}$ is required for Schwann cell growth: interactions between the cAMP and neuregulin/tyrosine kinase pathways. J Neurosci Res 1997;49:236-247

34. Zaminy A, Shokrgozar MA, Sadeghi Y, Noroozian M, Heidari MH, Piryaei A. Mesenchymal stem cells as an alternative for Schwann cells in rat spinal cord injury. Iran Biomed J 2013;17:113-122
35. Dong Z, Brennan A, Liu N, Yarden Y, Lefkowitz G, Mirsky $\mathrm{R}$, Jessen KR. Neu differentiation factor is a neuron-glia signal and regulates survival, proliferation, and maturation of rat Schwann cell precursors. Neuron 1995;15:585-596

36. Nave KA, Salzer JL. Axonal regulation of myelination by neuregulin 1. Curr Opin Neurobiol 2006;16:492-500

37. Levi AD, Bunge RP, Lofgren JA, Meima L, Hefti F, Nikolics K, Sliwkowski MX. The influence of heregulins on human Schwann cell proliferation. J Neurosci 1995; 15:1329-1340

38. Casella GT, Bunge RP, Wood PM. Improved method for harvesting human Schwann cells from mature peripheral nerve and expansion in vitro. Glia 1996;17:327-338

39. Casella GT, Wieser R, Bunge RP, Margitich IS, Katz J, Olson L, Wood PM. Density dependent regulation of human Schwann cell proliferation. Glia 2000;30:165-177

40. Ishaug SL, Crane GM, Miller MJ, Yasko AW, Yaszemski MJ, Mikos AG. Bone formation by three-dimensional stromal osteoblast culture in biodegradable polymer scaffolds. J Biomed Mater Res 1997;36:17-28

41. Toh YC, Ho ST, Zhou Y, Hutmacher DW, Yu H. Application of a polyelectrolyte complex coacervation method to improve seeding efficiency of bone marrow stromal cells in a 3D culture system. Biomaterials 2005;26:4149-4160

42. Talukdar S, Nguyen QT, Chen AC, Sah RL, Kundu SC. Effect of initial cell seeding density on 3D-engineered silk fibroin scaffolds for articular cartilage tissue engineering. Biomaterials 2011;32:8927-8937

43. Banoub RW, Fernstrom M, Ruch RJ. Lack of growth inhibition or enhancement of gap junctional intercellular communication and connexin 43 expression by beta-carotene in murine lung epithelial cells in vitro. Cancer Lett 1996; $108: 35-40$

44. van den Dolder J, Spauwen PH, Jansen JA. Evaluation of various seeding techniques for culturing osteogenic cells on titanium fiber mesh. Tissue Eng 2003;9:315-325

45. Sekiya I, Larson BL, Smith JR, Pochampally R, Cui JG, Prockop DJ. Expansion of human adult stem cells from bone marrow stroma: conditions that maximize the yields of early progenitors and evaluate their quality. Stem Cells 2002;20:530-541

46. Zhou H, Weir MD, Xu HH. Effect of cell seeding density on proliferation and osteodifferentiation of umbilical cord stem cells on calcium phosphate cement-fiber scaffold. Tissue Eng Part A 2011;17:2603-2613 